\title{
A EXPERIÊNCIA DIPLOMÁTICA DE JURACY MAGALHÃES: A POLÍTICA EXTERNA BRASILEIRA APÓS 1964 E A ASSINATURA DOS TRATADOS DE LISBOA
}

\author{
CARLOS NÁSSARO ARAÚJO DA PAIXÃO (IFBAIANO/LAPECS-UESB) \\ Instituto Federal Baiano - Campus Guanambi \\ carlos.hyst@gmail.com
}

\begin{abstract}
Resumo:
O artigo tem como principal objetivo analisar a atuação de Juracy Magalhães no ministério das Relações Exteriores, cargo que exerceu entre janeiro de 1966 até março de 1967. Será analisado o seu papel no processo de redefinição da política externa do Brasil, após 1964. Advinda daí, sua relação com os Estados Unidos será destacada, pois esta é considerada fundamental para explicar a sua postura à frente do planejamento, coordenação e execução da diplomacia brasileira. Estes elementos serão todos discutidos a partir de um estudo de caso, que possui um potencial de síntese, pois nele aparecem as principais questões referentes à política externa brasileira na década de 1960. Para tanto, serão analisados uma série de acordos que foram firmados entre os dois países, representados pelos ministros Juracy Magalhães, chanceler brasileiro e Franco Nogueira, o congênere português, em setembro de 1966.
\end{abstract}

\section{Palavras-Chave:}

Ditadura Militar - Política Externa - Juracy Magalhães - Economia

\begin{abstract}
:
This article aims to analyze Juracy Magalhães performance in ministery of External Relations, position that exercised among January 1966 through March 1967. Its role will be analyzed in the process of redefining Brazil's foreign policy after 1964. Arising therefrom, your relationship with the United States will be highlighted, because this is considered fundamental to explain your posture ahead of the planning, coordination and execution of the Brazilian diplomacy. These elements will be all discussed starting from a case study that possesses a synthesis potential, because in him they appear the main referring subjects to the Brazilian foreign policy in the decade of 1960. For so much, will be analyzed a series of agreements that were firm among the two countries, represented by ministers Juracy Magalhães, Brazilian chancellor and Franco Nogueira, the Portuguese congener, in September of 1966.
\end{abstract}

Keywords:

Military dictatorship - foreign policy - Juracy Magalhães - Economy 


\title{
A EXPERIÊNCIA DIPLOMÁTICA DE JURACY MAGALHÃES: A POLÍTICA EXTERNA BRASILEIRA APÓS 1964 E A ASSINATURA DOS TRATADOS DE LISBOA*
}

\author{
CARLOS NÁSSARO ARAÚJO DA PAIXÃO \\ (IFBAIANO/LAPECS-UESB) \\ Instituto Federal Baiano - Campus Guanambi \\ carlos.hyst@gmail.com
}

\section{Juracy Magalhães e a política exterior do Brasil após 1964}

O golpe civil-militar que derrubou o presidente João Goulart, em 31 de março de 1964 provocou uma redefinição na política externa brasileira. A partir do momento em que Castelo Branco assumiu a presidência e indicou Vasco Leitão da Cunha para o cargo de ministro das Relações Exteriores e Juracy Magalhães para assumir o posto de embaixador, nos Estados Unidos, iniciouse o processo de desmantelamento da chamada Política Externa Independente, em vigor no período imediatamente anterior, ou seja, nos governos Quadros e Goulart. Esta tinha por características a defesa do nacionalismo econômico, uma proposta de maior estreitamento de laços com os países da América Latina e a tomada de posição autônoma do Brasil em relação ao mundo bipolarizado durante a guerra fria, em especial à hegemonia estadunidense ${ }^{1}$.

Segundo definição do marechal-presidente, a independência na diplomacia seria um contrassenso diante da conjuntura marcada por um mundo bipolar, no qual era preciso escolher um lado na disputa. Além disso, a neutralidade pretendida anteriormente não fazia sentido, pois o Brasil era um país bastante ativo no mundo. Depois, o nacionalismo econômico provocava a fuga de capitais estrangeiros, considerados necessários para o crescimento econômico e industrial e a intervenção estatal prejudicava a entrada e o desenvolvimento das empresas privadas. E, por fim, em sua concepção, a defesa intransigente do anticolonialismo poderia gerar a ruptura dos históricos laços construídos com Portugal, envolvido na luta colonial em Africa, desde o início dos anos 1960. ${ }^{2}$

Segundo Amado Luiz Cervo (2010), entre os anos de 1964 e 1967, prevaleceram as seguintes diretrizes, definidas como instrumento norteador para a política externa brasileira:

"1. A Bipolaridade. Além de servir internamente, ao engendrar a noção de inimigo interno, de guerra civil, em que as Forças Armadas passaram a desempenhar funções policiais, a bipolaridade foi tão relevante externamente, ao ponto de bastar-se como estratégia.

\footnotetext{
* A presente publicação é resultado de uma pesquisa realizada em Portugal, com o apoio do Programa de Doutorado Sanduíche no Exterior (PDSE), por meio de uma bolsa de estudos concedida pela Coordenação de Aperfeiçoamento de Pessoal de Nível Superior (CAPES), fundação vinculada ao Ministério da Educação no Brasil e viabilizada pelo Programa de Pós-Graduação em Memória: Linguagem e Sociedade (PPGMLS), da Universidade Estadual do Sudoeste da Bahia (UESB).

${ }^{1}$ CERVO, Amado Luiz; BUENO, Clodoaldo. História da Política Exterior do Brasil. Brasília: Editora da UNB, 2010. p. 368.

${ }^{2}$ CERVO, Amado Luiz; BUENO, Clodoaldo. História... p. 368.
} 
Incorporou, com efeito, as categorias do ocidentalismo, da interdependência, da segurança coletiva, da aproximação com os Estado Unidos e da abertura econômica, de forma que se articulassem pela ideologia anticomunista e pela geopolítica. Castello tomou a bipolaridade como o dado da realidade determinante das condições objetivas e da vontade. [...]. As relações com os Estado Unidos, prioritárias neste esquema, destinavam-se, [...], a cruzar os interesses econômicos e comerciais com a afinidade política e a segurança coletiva. Vasco da Cunha assimilou o ocidentalismo ao anticomunismo, enquanto Castello o referiu à "fidelidade cultural e política ao sistema democrático ocidental". [...]. 2. A abertura ao capital estrangeiro. Essa dimensão não se apresentou, por certo, como uma novidade, a não ser como elemento da bipolaridade, e, ainda, enquanto se contrapunha ao nacionalismo e à estatização. [...]. E o governo Castello propôs-se então a criar as referidas condições, com a finalidade de induzir o desenvolvimento pelo livre jogo do mercado, sem Estado, sem fronteiras". ${ }^{3}$ (Grifos do autor).

Carlos Estevam Martins (1975) resumiu da seguinte maneira a definição da política externa durante o governo de Castelo Branco:

"No período Castelo Branco, a política externa tem como seu principal fundamento os interesses virtuais da burguesia internacionalizada, na qual se incluem, naturalmente, os grupos nacionais associados aos investimentos estrangeiros ou dependentes em moldes tradicionais, do setor externo da economia. Simultaneamente, verifica-se, pelo menos no interior do governo, uma estreita correlação entre a defesa da política exterior posta em prática e o apoio ao projeto de institucionalização de um modelo político elitista, mas de corte liberal-democrático. No campo da doutrina militar, prevaleceram teses defensivas, ligadas ao conceito de segurança coletiva. Finalmente, a ideologia dominante no período foi o chamado liberal-imperialismo". ${ }^{4}$

Os discursos de Juracy Magalhães ${ }^{5}$ proferidos na cerimônia em que assumiu o cargo de ministro e em outras ocasiões solenes do Itamaraty estavam em sintonia fina com a política exterior concebida por Castello Branco. Ele era, decerto, um continuador das propostas e ações empreendidas pelo grupo vencedor que ascendeu ao poder a partir de 1964. Na sua posse no ministério das Relações Exteriores, em 17 de janeiro de 1966, ele reafirmou o compromisso da diplomacia brasileira com a defesa do que denominou de "mundo livre", do ocidente e atacou a neutralidade pretendida pela política anterior.

"Nossa política externa é que espelha, aos olhos do mundo e aos nossos próprios, a plenitude da nossa imagem como povo e o sentido mais profundo do processo histórico que hoje vivemos. Essa política, tal como a definiu o Presidente Castelo Branco, no magistral discurso do Instituto Rio Branco, em julho de 1964, não pode perder de vista o fato primordial de que é um instrumento a serviço dos interesses nacionais brasileiros. E, para bem defendê-los, com legitimidade de propósitos e conveniência de resultados, tal política não pode ignorar as determinações de nossa realidade histórica, geográfica e cultural, que fazem do Brasil um membro nato do Mundo Livre, parte integrante da sociedade ocidental, à qual nos ligam a herança comum do passado e a identidade dos anseios para o futuro. [...]. Ato voluntário e consciente, essa filiação cultural ao Ocidente,

\footnotetext{
${ }^{3}$ CERVO, Amado Luiz; BUENO, Clodoaldo. História... p. 369-370.

${ }^{4}$ MARTINS, Carlos Estevam. "A Evolução da Política externa Brasileira na Década 64/74”. Estudos CEBRAP, n 12, 1975, São Paulo, p. 57.

${ }^{5}$ Neste artigo todas as citações de Juraci Magalhães foram retiradas do livro Minha Experiência Diplomática, publicado em 1971. Ele é composto por uma coletânea de discursos proferidos entre 1964 e 1967, quando ele assumiu os cargos de embaixador nos Estados Unidos e depois no ministério das Relações Exteriores.
} 
essa solidariedade política ao Mundo Livre - fundamento de nossa política externa - não lhe esgota o conteúdo nem constitui hipoteca de qualquer espécie, capaz de lhe tolher o passo, na consecução do objetivo maior, que é aquela defesa intransigente dos interesses nacionais. Por ser legítima e voluntária, essa opção fundamental tem a vantagem decisiva de escoimar, desde logo, nossa política externa de qualquer veleidade autárquica ou tendência neutralizante $[\ldots . .]^{\prime} \cdot{ }^{6}$

Estavam presentes nas palavras iniciais do novo chanceler a defesa do estreitamento de relação com o "mundo livre", algo como um sinônimo para ocidente, e a explicação que utilizou para descartar qualquer política de neutralidade frente às forçar que estavam em enfrentamento neste contexto. A defesa da bipolaridade implícita estava articulada com a política interna, baseada na definição do inimigo interno, por um lado, e no desenvolvimento associado e dependente, por outro $^{7}$. Adiante, na continuação de seu pronunciamento, foi apontada outra importante diretriz, a defesa intransigente do alinhamento com os Estados Unidos:

"O Brasil empresta especial importância às suas relações com os Estado Unidos da América, em quem reconhece o lider do Mundo Livre e o principal guardião dos valores fundamentais da nossa civilização. Entendo que essas relações, que tive o prazer de ver fortalecidas a partir de abril de 1964, devem ampliar-se a aprofundar-se permanentemente, num alto nível de confiança, amizade e respeito recíprocos. Para que assim ocorra, será fator de decisiva importância a presença em Washington do eminente Embaixador Vasco Leitão da Cunha, que leva para a chefia daquela Missão o prestígio do seu nome e as qualidades de um dos mais eminentes profissionais da nossa diplomacia". ${ }^{8}$ (Grifo nosso).

Nestas afirmações, o que primeiro se destaca é o deslindamento das relações intimas entre aqueles que perpetraram o golpe em 1964 e os Estados Unidos, e mais além, seria como se a continuação destas políticas dependesse do aval da potência imperialista do norte. Esses aspectos justificariam, na concepção de Juracy Magalhães, como um dos proponentes desta política externa, a colocação das relações com os Estados Unidos em um lugar prioritário, e, ao final, fica perceptível a solução de continuidade, no sentido de não haver ruídos e nem "desvio" de rota do Itamaraty.

O discurso de Juracy Magalhães estava ainda relacionado com as estratégias definidas e implementadas por Castelo Branco e os seus assessores "americanistas", com destaque para o exgovernador da Bahia, que tinha um histórico de relações com os Estados Unidos, tendo ocupado antes os cargos de adido militar e embaixador em Washington; Vasco Leitão da Cunha, além de Roberto Campos e Otávio Gouveia de Bulhões. Juracy Magalhães destacou, ainda, que ele e o seu antecessor foram convocados por Castelo Branco para formar "uma equipe capaz de criar nos Estados Unidos a imagem que merecia a Revolução Brasileira". A articulação entre política econômica interna, representada pelos dois últimos e a externa, cuja ação dos dois primeiros foi fundamental em sua definição nos primeiros anos da ditadura, foi definida em duas frentes principais, de acordo com Cervo:

“a) eliminar atritos nas relações entre o Brasil e a potência hegemônica do bloco ocidental para viabilizar a associação dos capitais, dos mercados, e da tecnologia, em harmonia com a afinidade política; b) enquadrar as relações interamericanas em esquema funcional - a

\footnotetext{
${ }^{6}$ MAGALHÃES, Juracy. Minha Experiência Diplomática: coletânea organizada e anotada por Clándio Garcia de Sousa. Rio de Janeiro: José Olympio Editora, 1971. p. 09-10.

${ }^{7}$ CERVO, Amado Luiz; BUENO, Clodoaldo. História... p. 373.

${ }^{8}$ MAGALHÃES, Juracy. Minha Experiência Diplomática... p. 11.

${ }^{9}$ MAGALHÃES, Juracy. Minha Experiência Diplomática... p. 273.
} 
serviço da bipolaridade - mediante a segurança coletiva e o mesmo tipo de vínculos econômicos". ${ }^{10}$

De acordo com René Armand Dreifuss, o Ministério do Exterior sofreu mudanças drásticas em sua orientação, deixando de lado suas políticas neutralistas e favoráveis ao terceiro mundo, por um alinhamento quase automático aos EUA. Juracy Magalhães deu prosseguimento e enfatizou essa política. $\mathrm{Na}$ qual o princípio da soberania nacional teve o mesmo destino dos interesses industriais e comerciais não envolvidas na internacionalização do mercado ${ }^{11}$.

Estas relações foram exaltadas já no discurso de apresentação de Juracy Magalhães ao presidente Lyndon Johnson, ao assumir o cargo de embaixador em Washington, em julho de 1964:

“O Brasil tem perfeita consciência da importância de suas relações com os Estados Unidos da América e é firme intenção de meu Governo desenvolvê-las tanto quanto possível. A identidade dos princípios que correspondem às aspirações de nossos povos e que regem a conduta de nossos governos muito facilitará esse propósito". ${ }^{12}$

Portanto, o ministro das Relações Exteriores foi incumbido de acertar a sintonia do Brasil em relação aos Estados Unidos, tarefa que ele começou a cumprir ainda nas suas primeiras ações após o golpe, ao assumir a embaixada brasileira em Washington:

"Felizmente, quando tive a honra de exercer as funções de embaixador em Washington, foi me dado o prazer de assistir ao revigoramento de nossas relações com os Estados Unidos, graças à sólida política em boa hora restabelecida pelo Governo Revolucionário, relações essas que procuramos fazer com que se ampliem e aprofundem, dentro da melhor tradição legada ao Itamarati pelo Barão do Rio Branco, num alto nível de confiança, amizade e respeito recíproco". ${ }^{13}$

$\mathrm{Na}$ defesa da reaproximação com os Estado Unidos como fundamento básico na orientação da política externa, Juracy Magalhães, apresentou algumas justificativas, entre as quais, a alegação do peso comercial que este país representava em nossas exportações e enquanto fonte de financiamento para o desenvolvimento industrial. Segundo ele, "os Estados Unidos já são, de longe, o maior e melhor freguês do Brasil, como de lá provém a maior parte dos investimentos estrangeiros em nosso país, juntamente com a maior soma de conhecimentos e experiência tecnológica". ${ }^{14}$ E continuou:

"Graças ao esforço de reaproximação com os Estados Unidos, que nos permitiu ser novamente ouvidos no inegável centro da política mundial, que é Washington, voltamos a contar com a efetiva colaboração financeira norte-americana, tão necessária para a realização de nossos anseios de desenvolvimento, ao mesmo tempo em que logramos incrementar as nossas exportações para aquele país, como se deu no caso do café e do cacau". ${ }^{15}$

Entretanto, o chanceler brasileiro parecia consciente do atraso relativo e das desvantagens que os produtos brasileiros enfrentavam no mercado internacional, frente àqueles produzidos no país do

\footnotetext{
10 CERVO, Amado Luiz; BUENO, Clodoaldo. História... p. 374.

${ }^{11}$ DREIFUSS, René Armand. 1964: A conquista do Estado - ação política, poder e golpe de classe. Petrópolis: Vozes, 1981. p. 441.

12 MAGALHÃES, Juracy. Minha Experiência Diplomática... p. 127

13 MAGALHÃES, Juracy. Minha Experiência Diplomática... p. 18-19.

14 MAGALHÃES, Juracy. Minha Experiência Diplomática... p. 19.

${ }^{15}$ MAGALHÃES, Juracy. Minha Experiência Diplomática... p. 33.
} 
norte e buscava "a concessão, pelos Estados Unidos, de preferências compensatórias das desvantagens que vários de nossos produtos de exportação encontram noutras áreas". ${ }^{16}$

Juracy Magalhães encarava a política exterior como uma extensão das questões internas. Neste caso, o binômio desenvolvimento/segurança, tão alardeado como motivo para a perpetração do golpe, em 1964, também foram elevados a diretriz da ação da chancelaria brasileira.

"De fato, política exterior não se improvisa, não é suscetível de inovações súbitas e suas diretrizes hão de ser parte e reflexo da política nacional, em seu aspecto global, surgindo necessariamente da confluência dos meios de ação e dos interesses nacionais com a conjuntura internacional". ${ }^{17}$

Entre estas ações, o Itamaraty agiu também como promotor e representante dos interesses econômicos dos grupos capitalistas monopolistas multinacionais e associados, no Brasil, e, Juracy Magalhães, como chefe de tal órgão, defendia as mesmas políticas.

"Essa maleabilidade sadia e franca da ação política exterior, esse cuidado de dar atenção tanto às questões políticas quanto aos assuntos econômicos, fez com que o Itamarati, nestes três últimos anos [1964-1967], reformulasse seu esquema de promoção comercial, incutindo em seus funcionários, dobrado interesse em proporcionar a nossos exportadores toda assistência por eles requerida, procurando, na medida de nossas possibilidades, suprir a relativa inabilitação notada em alguns dele. Nesse campo, a ação do Itamarati secundou sempre, dando-lhes necessária a cobertura, as iniciativas valiosas de diversos órgãos diretamente interessados no comércio exterior, como, por exemplo, o Ministério da Indústria e Comércio, o Instituto Brasileiro do Café, o Instituto do Açúcar e do Álcool, a Petrobrás, a Companhia Vale do Rio Doce". ${ }^{18}$

Em outra oportunidade, falando para empresários, em março de 1966, reforçou o papel do ministério das Relações Exteriores, e da sua gestão à frente do órgão, na promoção da iniciativa privada do Brasil, na defesa dos interesses da fração burguesa associada e dependente:

“E, por fim, para não prolongar esta série de exemplos da ação do Itamarati no campo econômico e comercial, quando busca novos mercados para nossos produtores e exportadores, proclamando sua competência, difundindo suas possibilidades, pondo-os em contato com eventuais fregueses. O Itamarati é cada vez, mais uma instituição a serviço dos homens de empresa brasileiros, numa demonstração eloquente de seu reconhecimento da importância que a iniciativa privada tem para a economia nacional e, daí, para o progresso do país. Como sinal de importância que dou a esse aspecto do trabalho do Itamarati, cunbei e tenho repetido a frase de que bom embaixador e bom cônsul são aqueles que vendem bem!?. ${ }^{19}$ (Grifo nosso).

E, além disso, destacou a sua ação nos Estados Unidos para viabilizar a venda de produtos brasileiros no mercado estadunidense, bem com a captação de recursos para financiamento de projetos de desenvolvimento, bem como a renegociação de dívidas.

"Graças à boa vontade que soube criar junto às autoridades americanas, vi o Governo brasileiro obter o reescalonamento das dívidas nacionais nos Estados Unidos, quando começou a arrancada para o restabelecimento do crédito do país no exterior; assisti ao

\footnotetext{
16 MAGALHÃES, Juracy. Minha Experiência Diplomática... p. 19.

17 MAGALHÃES, Juracy. Minha Experiência Diplomática... p. 31.

18 MAGALHÃES, Juracy. Minha Experiência Diplomática... p. 34.

${ }^{19}$ MAGALHÃES, Juracy. Minha Experiência Diplomática... p. 218-219.
} 
crescimento de nossas vendas de café, de cacau, de tecidos e de açúcar; e verifiquei pessoalmente, pelo acatamento e atenções de que me vi cercado, o quanto se modificou a imagem do Brasil na grande nação em que o representava". ${ }^{20}$

Para que estas concessões do mercado estadunidense se concretizassem, entretanto, foram necessárias contrapartidas para facilitar a entrada e a livre circulação de capitais provenientes daquele país, na economia brasileira. De acordo com Martins, o capital estrangeiro foi fundamental para a efetivação do modelo de desenvolvimento dependente e associado e, para tanto, a política econômica da Brasil "esmerava-se em criar um clima saudável para os negócios norte-americanos" 21 . Entre estas, se destacaram o combate à inflação através da compressão dos salários, gerando o barateamento da mão-de-obra e o limite ao acesso do crédito, cujo efeito se fez sentir em setores do empresariado brasileiro.

Além disso, alterou-se a lei de remessa de lucros, que suspendeu as restrições ao movimento dos capitais estrangeiros e a publicação da Instrução 289, da SUMOC, que possibilitava às empresas estrangeiras o usufruto de linhas especiais de créditos com juros muito baixos. ${ }^{22}$

\section{O processo de reaproximação diplomática com Portugal}

A partir da política exterior preconizada por Castelo Branco, Portugal voltou a ser tratado de maneira privilegiada, e, para isso, alegavam-se os laços históricos e afetivos entre os dois países. A aproximação chegou a tal nível que a Marinha do Brasil cogitou participar junto a portugueses e sul-africanos em ações militares no Atlântico Sul. ${ }^{23}$ Juracy Magalhães afirmou o seguinte sobre o que esperava da aproximação com Portugal:

"Por ter a nossa ancestralidade portuguesa no mais alto apreço, por amar e admirar Portugal, por me sentir vinculado à campanha de preservação dos liames de nossa comunidade é que tenho, em minha vida pública, procurado ser sempre um servidor leal e esforçado da nossa causa comum. Por acreditar que à cultura lusíada está reservado um papel singular na evolução da humanidade é que sempre me associo, convictamente, a quantos movimentos e iniciativas possam conduzir ao estreitamento das relações lusobrasileiras". ${ }^{24}$

Outro aspecto que interferiu na reaproximação entre Brasil e Portugal, para os formuladores da política externa brasileira, foi a articulação de uma identificação da guerra anticolonial com o comunismo internacional e a postura do Itamarati como integrantes do bloco capitaneado pelos Estados Unidos. Estes consideravam qualquer "luta de liberação" como uma estratégia da guerra fria promovida pelo bloco socialista para ampliar a sua influência no mundo, portanto, por este viés, a defesa de Portugal era mais que inevitável, era natural. ${ }^{25}$

Do ponto de vista português, o que mais interessava na reaproximação diplomática com o Brasil era, justamente, a possibilidade de se contar com mais um aliado que defendesse as suas posições coloniais nos organismos internacionais. E, justamente neste ponto, apareceram algumas arestas e ruídos nesta relação, que serão discutidas ao longo do artigo.

\footnotetext{
${ }^{20}$ MAGALHÃES, Juracy. Minha Experiência Diplomática... p. 276.

${ }^{21}$ MARTINS, Carlos Estevam. Op. Cit.p. 60.

22 MARTINS, Carlos Estevam. Op. Cit. p. 60-61.

23 MARTINS, Carlos Estevam. Op. Cit. p. 66.

${ }^{24}$ MAGALHÃES, Juracy. Minha Experiência Diplomática... p. 165.

${ }^{25}$ MARTINS, Carlos Estevam. Op. Cit.p. 66.
} 
Com o objetivo de angariar o apoio brasileiro, o ministro dos Negócios Estrangeiros embarcou em uma missão diplomática para o Brasil, em junho de 1965. Franco Nogueira buscava arrancar das autoridades brasileiras muito mais do que palavras de efeito e elogio à Portugal e à nossa "herança lusitana". Durante toda a viagem, ele se preocupou em angariar uma ação, ou mesmo uma declaração mais objetiva de apoio à situação portuguesa em África. ${ }^{26}$

Franco Nogueira, ao prestar contas dos resultados obtidos na visita diplomática ao Brasil, proferiu uma conferência pública e formal de imprensa, na qual deu explicações sobre a política externa portuguesa, e, especificamente, sobre as potencialidades e as condições para a formação de uma Comunidade Luso-Brasileira. ${ }^{27}$

Em primeiro lugar, empreendeu uma crítica à pouca efetividade dos discursos brasileiros em relação à questão crucial que realmente interessava a Portugal, a sua situação na África, e o fato de que esses apenas focavam no caráter emotivo das relações históricas e culturais entre os dois países. Em seguida, defendeu de maneira intransigente a posição portuguesa frente à pressão sofrida na comunidade internacional pela independência de suas colônias. Havia algo de orgulho nesta postura e esta se impunha enquanto uma condição indispensável para o sucesso das relações luso-brasileiras, em seu entendimento, Franco Nogueira convocava o Itamarati para o enfrentamento do que ele definia como modismos e ideologias oportunistas. ${ }^{28}$

Franco Nogueira envidava esforços para "demover a intenção brasileira de prosseguir uma política externa independente em África, política essa que podia ser tida como abertamente contrária aos interesses portugueses naquele continente" ${ }^{29}$. Ao mesmo tempo, criticava as estreitas relações e compromissos do Brasil para com os Estados Unidos, constituindo-se um elemento sempre complicador para a efetivação da propalada comunidade, visto que Portugal enxergava com desconfiança a ação dos estadunidenses em toda esta situação. Entretanto, temia que os principais nomes da diplomacia brasileira, como Vasco da Cunha e Juracy Magalhães, marcados pelo "americanismo" entravassem, ou não se empenhassem o suficiente para a consecução dos seus objetivos.

Oficialmente, o instrumento operacionalizado para selar o processo de reaproximação entre os dois países foi a efetivação do Tratado de Amizade e Consulta, assinado ainda em 1953, mas que não redundou em nenhuma ação prática desde então. De ambos os governos havia a intensão de utilizar-se deste Tratado para dinamizar as relações, marcada pelas intermitências políticas nos dois lados do Atlântico. ${ }^{30}$

Franco Nogueira também defendeu, além da efetivação, a ampliação das prerrogativas do Tratado, jogando com os possíveis interesses brasileiros, acenou com a possibilidade da exploração econômica dos territórios ultramarinos portugueses, eufemismo para se referir às colônias.

"É por isso que temos proposto o alargamento do Tratado de Amizade e Consulta a todos os territórios brasileiros e portugueses em todos os continentes; por isso temos proposto a

\footnotetext{
${ }^{26}$ NOGUEIRA, Franco. Um Político Confessa-se (Diário: 1960-1968). 3. Ed. Porto: Livraria Editora Civilização, 1987. p. 85 .

27 Este pronunciamento foi realizado em Lisboa, a 5 de agosto de 1965. Cf. NOGUEIRA, Franco. Um Político Confessa-se..., p. 133.

${ }_{28}$ NOGUEIRA, Franco. Política Externa Portuguesa. Lisboa: Ministério dos Negócios Estrangeiros, 1967. (vol. 2). p. 23.

${ }^{29}$ CASTRO, Zília Osório de; SILVA, Júlio Rodrigues da; SARMENTO, Cristina Montalvão. Tratados do Atlântico Sul: Brasil-Portugal, 1825-2000. Lisboa: Ministério dos Negócios Estrangeiros, 2006. p. 279.

${ }^{30}$ CASTRO, Zília Osório de. et. al. Op. Cit.
} 
criação de portos francos brasileiros, tanto na metrópole como no ultramar português, nos territórios onde forem julgados mais úteis; e para isso temos proposto uma acção externa comum para garantia e defesa do património territorial, cultural e moral que a ambas toca. E de quanto procede haveremos de extrair várias importantes conclusões". ${ }^{31}$

A proposta consistia em partilhar com o Brasil o potencial econômico de suas colônias na África. O chanceler português, ciente dos interesses brasileiros nos recursos naturais em abundância, como as reservas de petróleo em Angola, os colocava à disposição das autoridades brasileiras. No entanto, cobrava, necessariamente, uma contrapartida, qual seja, a defesa incondicional da política externa portuguesa, frente à comunidade internacional, na prática, em troca da exploração de suas colônias, Portugal exigia que o voto do Brasil, na ONU, se alinhasse ao seu.

"Quando sem restrições colocamos tudo o que somos e temos à disposição do Brasil presumimos que igualmente o Brasil encarará sem restrições tudo o que somos e temos porque uma política como a que sugerimos seria incompatível com quaisquer hesitações ou reservas por parte brasileira quanto a toda Nação Portuguesa, ou com fórmulas alheias mais ou menos oportunas que, no fundo, tem em vista a destruição daquelas mesmas posições portuguesas; e solicitamos com empenho aos nossos amigos brasileiros que acreditem que, uma vez destruídas, daquelas posições nada mais restaria para portugueses nem para brasileiros". ${ }^{32}$

Havia na passagem uma exigência de reciprocidade, além de uma abordagem prática no que diz respeito às pretensões brasileiras em expandirem os seus negócios. Era recorrente nas abordagens de Franco Nogueira, uma desconfiança em relação às reais intenções brasileiras em sua aproximação com Portugal. A sua leitura era a de que havia claramente uma pretensão do Brasil em se tornar uma subpotência a dominar o Atlântico Sul, enquanto que dependentes e perigosamente (para os interesses portugueses) atrelados à política externa dos Estados Unidos. Em sua concepção, nada mais justo que uma reciprocidade, na qual Portugal cederia parte dos seus privilégios coloniais, em troca do apoio de um parceiro, considerado cada vez mais importante.

Uma última cartada para conseguir o apoio do Brasil para a sua causa, foi apelar para a defesa do "mundo livre", segundo a chancelaria portuguesa, seriamente ameaçado pelos movimentos de libertação nacional que varreram a Ásia e a África a partir do final da Segunda Guerra Mundial, e que se intensificaram sobremaneira na década de 1960.

"E também pedimos aos brasileiros para acreditarem que aqueles princípios, que lhe são tão justamente queridos, são completamente esquecidos e negados e calcados por aqueles próprios que são entusiastas partidários de "ventos da história" ou de modas oportunistas que imaginaram para melhor servir os seus interesses; e por isso a colaboração do Brasil naquela orientação ou mesmo a sua simples anuência só poderiam contribuir para dar a vitória a quem não merece. Além do mais, seria um novo golpe profundo na civilização do mundo livre de que o Brasil é destacado defensor e impulsionador". ${ }^{33}$

Franco Nogueira buscava uma identificação com um dos mais caros pilares da política externa brasileira, preconizada por Castelo Branco, Vasco da Cunha e Juracy Magalhães, qual seja, o engajamento da diplomacia do Brasil na defesa do "ocidentalismo" e do chamado "mundo livre". Portanto, o chanceler português buscou relembrar aos brasileiros que a possibilidade da

31 NOGUEIRA, Franco. Política Externa Portuguesa... p. 24-25.

32 NOGUEIRA, Franco. Política Externa Portuguesa... p. 25.

${ }^{33}$ NOGUEIRA, Franco. Política Externa Portuguesa... p. 25. 
independência das colônias significava pôr em risco tudo aquilo que o Brasil defendia em matéria de teorizações sobre a realidade internacional. A descolonização que já havia golpeado Portugal com a perda do território de Goa para a União Indiana, era considerada um simples modismo oportunista.

Entre junho de 1965 e setembro de 1966 as autoridades do Brasil e de Portugal buscaram definir as regras e os detalhes para a assinatura dos acordos responsáveis por tornar efetivo o Tratado de 1953. Neste meio tempo ocorreram mudanças nos principais postos responsáveis pela definição da política externa brasileira. Vasco da Cunha deixava o ministério das Relações Exteriores, por outro lado, Juracy Magalhães deixava a embaixada em Washington e assumia a chancelaria brasileira. Do ponto de vista prático, nenhuma alteração significativa pôde ser observada nas diretrizes do Itamaraty. No entanto, as negociações foram marcadas por intensas discussões e desacordos. Exibindo claramente as divergências entre as autoridades dos dois países, Franco Nogueira declarou:

"Quase contínuas negociações com os brasileiros sobre o acordo cultural. São difíceis os homens do Brasil, e parece ficarem muito ofendidos quando não aceitamos os seus textos, ou lhes propomos umas singelas emendas. Mas lá vamos avançando alguma coisa. Chamei o embaixador do Brasil, e observei-lhe que em todas as declarações de fundo, a pronunciar pelo chanceler brasileiro [Juracy Magalhães] na sua próxima visita, não se incluía uma frase, uma referência, uma simples alusão ao ultramar e aos graves problemas que ali enfrentamos. Disse-lhe que estão obcecados e fascinados com o nosso ultramar; mas quando se trata de apoiar a nossa política, então fogem mais rápido do que o diabo foge da cruz. Concordou o embaixador, e disse que ia fazer os possíveis para remediar o que eu the apontava. Apesar de tudo, é natural que da visita, dentro de dias, alguns resultados se possam conseguir em favor da famosa Comunidade Luso-Brasileira". ${ }^{34}$

Neste relato, percebe-se que, do ponto de vista da real politik, as promessas portuguesas não surtiram o efeito desejado nas autoridades brasileiras, igualmente, as intenções do Brasil em estabelecer uma relação mais efetiva com Portugal não passavam de palavras que evocavam as identidades históricas e culturais entre os dois países. Além disso, a queixa se voltava para o fato de que ao Brasil apenas interessava a disponibilidade dos recursos naturais com potencial econômico, presentes nas colônias portuguesas na África, enquanto que não mostravam nenhuma intenção em apoiar internacionalmente a política colonial portuguesa. A ausência de um compromisso formal do Brasil nesta questão se constituiu em uma tensão constante na formulação de uma pretensa comunidade luso-brasileira.

\section{Juracy Magalhães e a assinatura dos Acordos de Lisboa}

O Ministro das Relações Exteriores, Juracy Magalhães desembarcou em Lisboa no dia 03 de setembro de 1966, sua estadia na capital portuguesa se estendeu até o dia 08 , do mesmo mês. O principal objetivo da viagem foi a assinatura de uma série de acordos bilaterais entre Brasil e Portugal, nas áreas comercial, cultural e técnica. Estes seriam os instrumentos práticos que deveriam ativar o Tratado de Consulta, assinado ainda na década de 1950. A assinatura transformou-se em um evento de grande importância, pois havia interesses de ambas as partes para a concretização do acordo. Os preparativos estavam em negociação desde junho de 1965, ocasião em que o chanceler português fez uma viagem ao Brasil e, a partir deste período, as autoridades diplomáticas nos dois lados do Atlântico envidaram esforços para avançar nas negociações que resultaram nos documentos finais. Para fins de análise neste artigo, o foco será direcionado apenas para os pontos relacionados com questões econômicas e comerciais.

${ }^{34}$ NOGUEIRA, Franco. Politica Externa Portuguesa... p. 186. 
O chanceler português, ao relatar a chegada do colega brasileiro, em seu diário, emitiu juízos de valor sobre a postura de Juracy Magalhães ao ser recepcionado, articulando-a com a posição política do Brasil. Além de uma renitente desconfiança em relação aos reais interesses brasileiros, principalmente ao tratar das colônias portuguesas em África.

"Lisboa, 3 de Setembro - De madrugada, pelas 6,30 horas, chegou o chanceler brasileiro Juracy de Magalhães. Bem-disposto; declarações simpáticas mas inócuas; de forma geral, reserva mental quanto ao nosso ultramar. Ao fim e ao cabo, os brasileiros querem que Moçambique e Angola, sobretudo Angola, se tornem independentes de Portugal e dependentes do Brasil". ${ }^{35}$

O que se percebia, ao longo de todo o período em que Juracy Magalhães esteve em missão diplomática, era um clima de tensão. Havia por parte das autoridades portuguesas, principalmente do seu chanceler, e da imprensa, uma urgência em conseguir do ministro brasileiro uma declaração muito literal de defesa incondicional da política colonial. Ele era instado todo o momento a dar declarações acerca deste tema. No mesmo sentido, transparecia certo temor em relação às intenções do Brasil em explorar os recursos econômicos em Angola e Moçambique.

A abordagem da imprensa, neste caso, foi muito semelhante, ou seja, destacou-se a sua simpatia no contato com jornalistas e autoridades, mas, sempre prudente, não proferiu palavra que o comprometesse.

"O ministro das relações exteriores do Brasil desembarcou do jacto da T.A.P. que o trouxe do Rio com um sorriso aberto e foi com esse mesmo sorriso simpático que abraçou o seu colega Franco Nogueira. Habituado aos contactos com os homens da imprensa, Juracy Magalhães foi prudente, mas claro, nas suas declarações aos jornalistas". ${ }^{36}$

Por outro lado, de fato, Juracy Magalhães esquivava-se e, em geral, não ia muito além de palavras amigáveis, mas sem muito efeito prático, para solucionar aquilo que era questão mais candente para os portugueses naquela conjuntura específica.

"As minhas primeiras palavras, ao chegar a Lisboa, devem traduzir necessariamente a saudação que o povo brasileiro faz por meu intermédio aos seus irmãos portugueses. Mais que um gesto de cortesia, é um abraço fraternal de que me honra de ser o portador e ao qual junto as minhas saudações pessoais". ${ }^{37}$

Depois disso, passou a relatar temas da história portuguesa e da importância desta herança para a cultura brasileira e das contribuições de Portugal para a preservação da civilização cristã e ocidental. Em seguida, ele tratou com os jornalistas especificamente sobre os objetivos que o levaram à visita. No entanto, desta vez, ainda nenhuma menção à África.

"Os acordos a serem celebrados darão ensejo a uma reactivação dos propósitos seculares que nos levaram, em 1953, à assinatura do Tratado de Amizade e Consulta. Dele resultara uma integração maior de nossos dois países: inspirou-se na conviç̧ão recíproca de que declarações de princípios nos tempos em que vivemos somente sobreviverão quando inspirarem aç̧ão realista e positiva. Estou certo de que as

\footnotetext{
${ }^{35}$ NOGUEIRA, Franco. Um Politico Confessa-se... p. 187

${ }^{36}$ Diário de Notícias, Lisboa, 04/09/1966, p. 1.

${ }^{37}$ Diário de Notícias, Lisboa, 04/09/1966, p. 1.
} 
iniciativas que derivarem dos Convênios em fim de elaboração concretizarão os propósitos do progresso dos dois países irmãos". ${ }^{38}$ (Grifo nosso).

Era consenso entre os dois ministros, a certeza de que a relação Brasil-Portugal necessitava de instrumentos diplomáticos mais práticos e era dessa forma que a assinatura dos acordos era encarada. Entretanto, a convergência de interesses parava nesta constatação. Enquanto os portugueses buscavam no Brasil um parceiro para enfrentar conjuntamente as sanções internacionais, os brasileiros desejavam a abertura do mercado angolano e moçambicano para os seus produtos de exportação, tanto os primários, quanto aqueles produzidos pela crescente industrialização. Isso pode ser percebido a partir desta reportagem do Jornal do Brasil, ao noticiar a viagem de Juracy Magalhães.

"O Ministro Caldeira Coelho referia-se ao acordo comercial que o Chanceler Juraci Magalhães assinará aqui [Lisboa] no dia 7 de setembro e que e mantido em segredo pelos portugueses. Sabe-se que um dos pontos principais é a criação de zonas francas de comércio que poderá tornar livre ao Brasil o Porto de Luanda, garantindo o acesso ao mercado africano". ${ }^{39}$

As autoridades portuguesas buscavam convencer o governo brasileiro a apoiar suas posições em África. Para tanto, atrelavam a sua causa à ideia de que seu império colonial seria um bastião contra o avanço do comunismo, e, sabedores do viés anticomunista e conservador do regime instalado no Brasil após 1964, convocaram o parceiro para a missão de afastamento da ameaça vermelha em terras portuguesas na África, o que em sua lógica significava, também, afastar o perigo vermelho das fronteiras brasileiras, tal como defendeu Franco Nogueira na conferência acima analisada.

Enquanto isso, a imprensa brasileira destacava as reais possibilidades de ampliação de mercados para os produtos brasileiros. Era, portanto, considerado o ponto principal da missão diplomática de Juracy Magalhães: garantir a criação de zonas francas na África aos principais produtos da pauta de exportações do Brasil, além do acesso aos produtos primários africanos, conforme tais afirmações abaixo:

"Apesar do interesse de Portugal, sabe-se que o tema africano não será discutido nessa viagem do Chanceler Juraci Magalhães. A visita não pode ser encarada como um passo na aproximação dos dois países. A reaproximação existe desde o triunfo da revolução [sic] de 64, que instalou o Presidente Castelo Branco no Poder [...]. Dentro do plano econômico, o Brasil terá de dispor de posições que lhe assegurem o acesso aos mercados de exportação ou abastecimento de algumas matérias-primas". ${ }^{40}$

Os discursos proferidos pelos dois ministros, em 5 de setembro, na solenidade de entrega de condecorações, por parte do governo brasileiro, a diversas autoridades portuguesas, apresentaram algumas convergências, como no caso da defesa da "Comunidade Luso-Brasileira", e da urgência na assinatura dos acordos, cujo objetivo seria a dinamização das relações bilaterais, muitas vezes obstaculizada pela excessiva burocracia e por que, como afirmou Franco Nogueira: "temos sofrido no decurso do tempo alguns embates ásperos, em que os interesses e os desígnios alheios se ocultam mal sob o disfarce de altas ideologias" ${ }^{21}$. O ministro português, caracterizando Juracy

\footnotetext{
38 Diário de Notícias, Lisboa, 04/09/1966, p. 1.

39 Jornal do Brasil, Rio de Janeiro, 02/09/1966, p. 15.

40 Jornal do Brasil, Rio de Janeiro, 02/09/1966, p. 15.

${ }^{41}$ O Século, Lisboa, 06/09/1966, p. 8.
} 
Magalhães como o paladino defensor da dita comunidade, expressou estas questões da seguinte maneira:

"Dentro de algumas horas, sr. ministro, assinaremos importantes acordos que, em execução do Tratado de Amizade e Consulta, regularão as relações comerciais, económicas e culturais entre o Brasil e Portugal. Esses acordos lançam novas bases ousadas e constituem um impulso vigoroso à integração comunitária luso-brasileira. [...]. hão-de traduzir a vitalidade crescente e a aproximação cada vez mais íntima entre os dois povos. É a expressão e o ímpeto dessa vitalidade que, por nossa parte, oferecemos ao Brasil’”. ${ }^{42}$

Juracy Magalhães, por sua vez, destacou que comungava das opiniões do seu colega português e que era necessário robustecer as relações diplomáticas entre os dois países para fazer a comunidade luso-brasileira sobreviver:

"Por isso mesmo, inconformados com a verificação de que, decorridos treze anos da celebração do Tratado de Amizade e consulta entre nossos dois países, ainda permanecia estagnada e regulamentação de muitos de seus dispositivos, unimos Vossa Excelência e eu, em representação de nossos governos e atendendo às aspirações dos dois povos irmãos, nossos pareceres de que urgia fazer alguma coisa para que o espírito do Tratado pudesse prevalecer nas relações luso-brasileiras, sob pena de vermos esboroar-se o esforço memorável de quantos através do tempo, haviam, direta ou indiretamente, contribuído para que aquele convênio se formalizasse". ${ }^{43}$

Por um lado, Franco Nogueira voltou a defender que o Brasil apoiasse a causa portuguesa, inclusive com o compromisso de participar da defesa conjunta da costa da África, justificando a existência de uma suposta fronteira ideológica que delimitaria tal comunidade.

"Por isso já temos dito que as fronteiras dos dois Países não são as fronteiras geográficas de cada um, mas as que delimitarem a Comunidade Luso-Brasileira. Sendo assim, haveremos de concluir que não é do interesse de um ou de outro contribuir ou sequer permitir que a comunidade seja limitada ou amputada no plano do espírito e no âmbito do território; e que o interesse de qualquer não é superior nem diferente do outro; e que dificilmente será viável defender esse interesse contra o outro ou sem ele. [...]. Cada um dos dois Países deverá estar pronto a sacrificar alguns dos seus interesses em favor do outro, mas não há motivo válido para que interesses luso-brasileiros sejam sacrificados em favor de terceiros". ${ }^{44}$

Novamente, o chanceler lusitano repetira quase que de maneira literal as ideias proferidas em agosto de 1965, acerca da sua concepção do que seria uma comunidade luso-brasileira ideal. Nesta ocasião, com a presença do chefe da diplomacia brasileira, o recado foi muito direto: Portugal contava com o apoio irrestrito do Brasil. Ele defendia, inclusive, uma postura de abnegação, a partir da qual, o Brasil abriria mão de parte de seus interesses na defesa das fronteiras comunitárias, em África.

Quais interesses eram contrários aos luso-brasileiros? Não foram ditos de maneira clara, mas subentende-se que se tratava, de um lado, da propalada e repetida ameaça comunista, que se aproveitara e se infiltrara nas lutas pela emancipação de suas possessões coloniais. Do outro, um

42 O Século, Lisboa, 06/09/1966, p. 8.

43 O Século, Lisboa, 06/09/1966, p. 8.

${ }^{44}$ O Século, Lisboa, 06/09/1966, p. 8. 
temor pela ação imperialista dos Estados Unidos, de acordo com Salazar e Franco Nogueira, sempre à espreita para se apossar dos recursos econômicos do ultramar. ${ }^{45}$

Da parte de Juracy Magalhães, entretanto, nenhuma palavra sobre esta questão. Nada além de amenidades, a não ser quando reiterava o seu objetivo em buscar resolver os problemas graves que estavam atingindo o Brasil, naquele contexto, tais como: a explosão demográfica, questões de abastecimento e educação. Apesar das palavras elogiosas ao seu colega português, ignorou solenemente o apelo para que "cada um dos dois Países deverá estar pronto a sacrificar alguns dos seus interesses em favor do outro". ${ }^{46}$

Para a imprensa brasileira, o mais importante era o fato de que os acordos comerciais a serem assinados no dia 7 de setembro já estavam prontos e destacavam que os pontos mais relevantes eram: "criação das zonas francas de comércio, pagamentos de transações em moeda livre e facilidades para a complementação industrial entre os dois países" ${ }^{\prime 7}$. O interesse principal era a retirada dos entraves para a livre circulação do capital associado ao estrangeiro, na política externa, complementando as ações efetivadas internamente. Isto fica patente no tratamento quase entusiasmado dado à questão das zonas francas:

"A criação de zonas francas de comércio é o tópico mais discutido. Trata-se de uma proposta antiga, só agora aproveitada. Através do Porto de Luanda, que seria uma das zonas francas, o Brasil teria acesso ao mercado africano, onde venderia os seus produtos manufaturados e obteria cobre e petróleo, principalmente o primeiro". ${ }^{48}$

A expectativa estava de acordo com a estratégia da política externa defendida pelo Itamaraty, que via no Ministério das Relações Exteriores um órgão voltado para o fomento das atividades comerciais do Brasil, para além de suas fronteiras. O próprio ministro, Juracy Magalhães, declarou em diversas oportunidades que cada embaixador e/ou cônsul deveria ser um vendedor dos produtos brasileiros. Do mesmo modo, entrava na discussão a possibilidade da ampliação da pauta de exportações brasileira, visto que, na conjuntura em que a industrialização se consolidava como uma atividade econômica de peso se vislumbrava a possibilidade de exportarmos produtos com maior valor agregado, ao invés de basearmos a nossa economia apenas em café, cacau e minérios brutos.

Por outro lado, na tentativa de internacionalizar as estatais brasileiras da mineração e do petróleo, havia claro interesse na exploração dos recursos minerais africanos e, para isso, era preciso tirar os empecilhos, tais como o controle colonial português, ou criar medidas como as zonas francas que garantissem a livre ação destas empresas ${ }^{49}$. Havia, ainda, a posição favorável de Juracy Magalhães, de que a Petrobrás pudesse investir na prospecção de petróleo em terras estrangeiras, diante na impossibilidade de encontrar jazidas rentáveis no subsolo brasileiro ${ }^{50}$.

O Jornal do Brasil destacou, ainda, o fato de que as regras e delimitações das zonas francas, como quantidade e locais de implantação, seriam discutidas e estudadas a partir da formação de uma Comissão Mista formada por membros dos governos dos dois países. Todavia, o chanceler brasileiro era da opinião de que esta tarefa deveria ser destinada aos empresários diretamente interessados nos desdobramentos práticos advindos da assinatura dos acordos. Em várias

45 TORGAL, Luís Reis. Estados Novos, Estado Novo: Ensaios de História Política e Cultural. Coimbra: Imprensa da Universidade de Coimbra, 2009. (vol. 1). p. 552-560.

46 O Século, Lisboa, 06/09/1966, p. 8.

47 Jornal do Brasil, Rio de Janeiro, 06/09/1966, p. 7.

48 Jornal do Brasil, Rio de Janeiro, 06/09/1966, p. 7.

49 Talvez, por isso, se explique o silêncio sobre política colonial.

${ }^{50}$ GUEIROS, José Alberto. O Último Tenente. Rio de Janeiro: Record, 1996. p. 273-276. 
oportunidades Juracy Magalhães defendeu a participação mais efetiva da iniciativa privada nas atividades econômicas do país. Ele advogava parcerias com os empresários, justificando que o know-how destes seria imprescindível para o desenvolvimento das forças produtivas brasileiras, destacando sempre a presença empresarial nos conselhos técnicos e diretamente nas estatais.

Juracy Magalhães concebia que o Estado deveria se imiscuir em questões econômicas somente o necessário, salvo em situações e setores estratégicos. Ele defendia a presença da iniciativa privada na definição da política econômica do país, tanto que levou um importante empresário, representante das industrias em sua missão diplomática, Rafael Nochesi, Presidente do Centro das Indústrias de São Paulo, o CIESP. ${ }^{51}$

Sobre tal questão, Dreifuss afirmou que "os interesses multinacionais e associados foram capazes de controlar a vida política do Estado e de forjar sua máquina de acordo com as necessidades do capital monopolista, [...]". ${ }^{52}$ Ele ainda destacou que "após 1964 o poder estatal direto transformou-se na mais alta expressão do poder econômico da burguesia, financeiro-industrial multinacional e associada". ${ }^{53}$ Juracy Magalhães, participante ativo do golpe e organizador da política do regime daí advindo, era um legítimo representante destes interesses.

Finalmente, a 7 de setembro de 1966, no Palácio das Necessidades, sede do Ministério dos Negócios Estrangeiros, de Portugal, os ministros Juracy Magalhães e Franco Nogueira assinaram os acordos nas áreas do comércio, da cultura e da cooperação técnica, entre Brasil e Portugal. A peça diplomática que despertou mais expectativa, tanto no Brasil, quanto em Portugal, foi o Acordo Comercial. Ele foi ratificado em Portugal, no dia 14 de setembro de 1967, a partir do Decreto-Lei 47.936. Em seu preâmbulo, estavam definidos os objetivos que levaram os dois países assinarem o documento. ${ }^{54}$

"O Governo do Brasil e o Governo de Portugal, animados do propósito de emprestar maior dinamismo às relações económicas entre os dois países e de aproveitar ao máximo a complementariedade actual e potencial das suas economias. [...]. Resolvem concluir um acordo de comércio a vigorar no território brasileiro e nos territórios portugueses do continente e ilhas adjacentes e das províncias ultramarinas [...]". ${ }^{55}$

Partia-se do princípio de que as realidades econômicas dos dois países haviam passado por significativas transformações, desde a assinatura dos últimos tratados, firmados em 1949 e, depois, em 1954. Razão pela qual se considerava que os seus antecessores perderam a capacidade de dinamizar as relações bilaterais.

Em seu artigo primeiro, definiu-se um compromisso entre os dois governos para tomarem medidas que visassem "promover o crescimento e a diversificação do intercâmbio comercial entre os dois países, levando em conta, especialmente, as necessidades criadas pelo processo de transformação das suas respectivas economias" $" 56$. O artigo segundo versava sobre a possibilidade da utilização de moeda de livre convertibilidade nas transações comercias a serem efetuadas entre os dois países. Já o terceiro possibilitava a celebração de acordos "de complementação industrial entre empresas brasileiras e portuguesas". Para que este fosse efetuado, havia, ainda, a previsão

\footnotetext{
51 Jornal do Brasil, Rio de Janeiro, 06/09/1966, p. 7.

52 DREIFUSS, René Armand. Op. Cit, p. 419.

${ }^{53}$ DREIFUSS, René Armand. Op. Cit, p. 419.

54 As cópias dos Acordos foram consultadas no Arquivo Histórico Diplomático, do Ministério dos Negócios Estrangeiros, em Lisboa, Portugal. Doravante serão referenciados pelas siglas AHD e MNE, respectivamente.

55 MNE, AHD, Diário do Governo, I Série, no 215, 14/09/1967, p. 1651.

${ }^{56}$ MNE, AHD, Diário do Governo, I Série, no 215, 14/09/1967, p. 1651.
} 
para que os governos solicitassem a "colaboração dos correspondentes sectores privados", sob a justificativa de agilizar a realização dos objetivos. ${ }^{57}$

$\mathrm{O}$ artigo mais comentado pela imprensa brasileira, e aquele que, de fato, interessava ao governo do Brasil foi o quarto, que previa a criação de zonas francas em território brasileiro e português. O teor do artigo era o seguinte:

"A fim de facilitar a criação de zonas francas para produtos originários do Brasil e de Portugal, a que se refere o artigo no 8 do Tratado de Comércio de 26 de Agosto de 1933, logo que uma das partes manifeste interesse pelo estabelecimento de uma dessas zonas em qualquer parte do território brasileiro os dos territórios portugueses, o Governo do Brasil e o Governo de Portugal promoverão a constituição de grupos de trabalho especializados, formados por peritos dos dois países, com o objetivo de acordarem nas soluções de todos os problemas que para esse efeito tiverem de ser considerados". ${ }^{58}$

Destaque para a promessa, formal, de abertura do mercado em todos os territórios sob o domínio português. De acordo com discussões realizadas acima, sabe-se que o maior interesse dos brasileiros era exatamente a possibilidade da exploração do mercado nas colônias portuguesas, nomeadamente Angola, cujo subsolo era rico em cobre e petróleo, além de ser um mercado consumidor em potencial para os produtos de nossa pauta de exportações.

O artigo quinto abordava a concessão de facilidades para a realização de feiras e exposições, bem como a dispensa de taxas de importação para material de propaganda, além da simplificação das formalidades aduaneiras. O sexto versava sobre a instituição e a composição da Comissão Econômica Luso-Brasileira, responsável por fomentar as relações econômicas entre Brasil e Portugal e delimitava quem poderia ser membro e quais as funções da mesma: " 1 o Serão membros da Comissão: a) Os representantes dos diversos órgãos oficiais do Brasil e de Portugal particularmente interessados; b) Os representantes das entidades privadas para tal pelos respectivos Governos". ${ }^{59}$

A comissão teria um papel de planejamento e execução no processo de estabelecimento de um mercado comum entre Brasil e Portugal. Um dos fatores mais importantes era a compreensão de que ambos os países passavam por transformações econômicas significativas e, portanto, era necessário que qualquer compromisso bilateral firmado deveria levar em consideração esta dinâmica. Após muitos anos de isolacionismo, Portugal estava em lento processo de abertura de sua economia, desde o final da década de 1950 e o Brasil, com o golpe de 1964, acelerou o processo de internacionalização econômica.

Apesar da insistência da imprensa portuguesa, não era do interesse do Brasil se envolver em qualquer ação prática, diga-se, conflito militar ou envio de tropas, armamentos ou equipamento bélico, para defender as posições portuguesas no sul da África. O próprio teor dos acordos assinados já antecipa esta postura, visto que o ministro brasileiro foi para Portugal, principalmente, para negociar com os portugueses a possibilidade de que as possessões lusitanas no continente africano fossem exploradas economicamente pelas empresas brasileiras, em associação com o capital internacional, isso, ao menos no papel, foi realizado. Portanto, por mais que as autoridades e a imprensa portuguesa pressionassem, não conseguiram demover Juracy Magalhães dos seus objetivos iniciais.

\footnotetext{
${ }^{57}$ MNE, AHD, Diário do Governo, I Série, no 215,14/09/1967 p. 1651-1652.

58 MNE, AHD, Diário do Governo, I Série, no 215, 14/09/1967, p. 1652.

${ }^{59}$ MNE, AHD, Diário do Governo, I Série, no 215, 14/09/1967, p. 1652.
} 
No título da chamada da matéria, o Jornal do Brasil, ao tratar da temática, ressaltou que: "Juraci assinará hoje acordo que leva o Brasil até Angola" ${ }^{\text {"0 }}$. As especulações giraram em torno dos possíveis desdobramentos para a economia brasileira de uma abertura do mercado angolano:

"Esse acordo deverá liquidar o mito das economias paralelas - disse o Sr. José Maria Penteado [representante do CIESP] - mito que obscurece nossas relações comerciais com a África. Poderemos continuar produzindo café com a participação dos angolanos, que nos oferecem tipos especiais para a mistura. [...]. No mercado mundial, agiremos como economias integradas". ${ }^{61}$

Foi motivo de preocupação por parte dos cafeicultores brasileiros a possível concorrência do café produzido em Angola e especulou-se sobre o que era considerado um absurdo: a possível importação desse produto, por parte do mercado brasileiro. A opinião do representante empresarial, que acompanhou toda a missão diplomática, corroborava com as declarações que Juracy Magalhães prestou à imprensa de Portugal:

“A [sessão] luso-brasileira da Conferência de Imprensa terminou com considerações acerca da produção e comércio do café, ponto em que - o chanceler lembrou-o, sorridente - o Brasil e Angola são concorrentes. [...], e no que se liga com a concorrência Angola-Brasil, o chanceler pensa que a conciliação dos interesses não será impossível" ${ }^{62}$.

Mas, destacando-se o fato de que setores empresariais do país já estavam se mobilizando e produzindo estudos técnicos visando a definição de que produtos deveriam ser destinados à exportação.

"Através do Porto de Luanda, que será livre com a assinatura do acordo, um mercado potencial de 50 milhões de pessoas o Sul da África estará aberto ao Brasil. Ainda não se decidiu exatamente quais serão os produtos a serem colocados lá, mas já se criou em São Paulo um centro de informação técnica para estudar o assunto". ${ }^{63}$

Este excerto da matéria jornalística aponta para duas questões muito significativas relacionadas com a definição da política externa e da política econômica, e da articulação entre estas duas esferas, após 1964. Inicialmente, se destaca a presença de setores da iniciativa privada no planejamento e na definição de estratégias para o desenvolvimento econômico do país. Não por acaso, a principal fonte de informações para a cobertura do Jornal do Brasil à viagem de Juracy Magalhães foi José Penteado, representante do Centro das Indústrias do Estado de São Paulo (CIESP), membro da comitiva brasileira, que em muitas ocasiões atuou como consultor para o chanceler brasileiro. Em seguida, é possível perceber a concepção de que o Brasil deveria assumir um papel de protagonismo no Atlântico Sul, em uma espécie de subimperialismo, cuja influência deveria se estender para o cone sul, na América Latina e costa atlântica da África. Essas ideias eram defendidas pela imprensa ligada aos interesses da burguesia industrial-financeira associada.

O interesse brasileiro voltou-se novamente para as reservas de cobre e petróleo presentes no subsolo angolano. Na verdade, a perspectiva de exploração desses minerais despertou os interesses dos empresários brasileiros e os seus associados internacionais desde que os acordos foram anunciados, uma vez que, a presença de empresários na comitiva oficial, indica a sua participação no processo de negociações e de conformação das cláusulas dos documentos.

\footnotetext{
${ }^{60}$ Jornal do Brasil, Rio de Janeiro, 07/09/1966, p. 4.

${ }^{61}$ Jornal do Brasil, Rio de Janeiro, 07/09/1966, p. 4.

${ }^{62}$ Diário Popular, Lisboa, 07/09/1966, p. 13.

${ }^{63}$ Jornal do Brasil, Rio de Janeiro, 07/09/1966, p. 4.
} 
"O cobre e o petróleo de Angola deverão ser explorados por companhias brasileiras e portuguesas, ainda como consequência do acordo. [...]. Onde os dois países podem arranjar dinheiro para apurar se há ou não cobre? O Sr, José Maria Penteado [novamente] pergunta e ele mesmo responde acreditar que grandes empresas internacionais estejam dispostas a financiar as pesquisas, desde que se apresentem boas perspectivas. No caso do petróleo de Angola, o problema será outro. As próprias sondas brasileiras poderão cuidar da prospecção em terreno africano. Não se sabe ainda se a Petrobrás terá interesse no petróleo de Angola ou condições de investigar todo o solo brasileiro, a fim de partir para uma sondagem internacional". ${ }^{64}$

Neste caso, apontava-se para um problema estrutural na economia dos dois países. Havia interesse claro em se explorar os minérios, principalmente o cobre, mas era necessária uma prospecção mais detida para saber da sua viabilidade econômica. Acontece que, tanto Brasil quanto Portugal, eram economicamente dependentes e o seu processo de industrialização ocorreu a partir do maciço financiamento a partir do capital monopolista estrangeiro.

Apesar de possuírem um parque industrial cada vez mais consolidado, ainda não possuíam recursos suficientes para financiarem empreendimentos desta monta, portanto, a presença do capital externo era inevitável neste tipo de empreitada. Mais do que isso, esta associação era inclusive buscada, por isso foi a solução natural apontada pelo representante do empresariado brasileiro.

Antes mesmo da efetivação formal dos convênios, já ocorriam reuniões entre empresários portugueses, brasileiros e de outras nacionalidades, na Associação Comercial de Lisboa, cujo objetivo era definir imediatamente os primeiros planos de trabalho, após a vigência dos acordos. Os próprios diretores da gigante Loide, na Europa, deslocaram-se para a capital portuguesa para assistirem pessoalmente à assinatura dos documentos, o que demonstra que o capital monopolista internacional percebia este acordo como mais uma possibilidade de ganho.

Em relação ao petróleo, estas dúvidas levantadas eram parte da definição da estratégia de mercado e de atuação da Petrobras. De um lado, havia aqueles que defendiam que a empresa deveria investir, em primeiro lugar, na prospecção do petróleo no território brasileiro, que era preciso esgotar todas as possibilidades de investigação e pesquisa para buscar este produto em subsolo nacional. Por outro lado, baseados nos dados obtidos e divulgados pelo Relatório Link, ${ }^{65}$ entre eles o próprio Juracy Magalhães, estavam aqueles que eram da opinião de que, na ausência ou insuficiência de petróleo em determinadas áreas do país, seria possível a atuação da estatal em território estrangeiro.

Ao final da solenidade de assinatura dos acordos, o Ministério dos Negócios Estrangeiros de Portugal publicou na imprensa um comunicado oficial, versando sobre o balanço das ações que tiveram por objetivo o estreitamento e dinamização das relações bilaterais entre Brasil e Portugal. O seguinte excerto pode ser considerado um bom resumo do que foi o encontro, pois abordou, especificamente, os principais temas tratados na visita diplomática do chanceler brasileiro, em terras lusitanas:

\footnotetext{
${ }^{64}$ Jornal do Brasil, Rio de Janeiro, 07/09/1966, p. 4

${ }^{65}$ Relatório produzido por Walter Link, engenheiro estadunidense, ex-funcionário da Standard Oil e contratado para ser o chefe do Departamento de Exploração da Petrobrás, quando Juracy Magalhães presidia a empresa. Neste documento, Link relatava que nem todo o território nacional possuía reservas economicamente viáveis e que a continuação da prospecção iria exaurir os cofres da estatal. Recomendava concentrar esforços e recursos nos campos petrolíferos já conhecidos da Bahia e, alternativamente, dizia da possibilidade de rentabilidade na pesquisa e exploração em outras áreas fora do país. Cf. GUEIROS, J. A. O Último Tenente..., p. 273-276.
} 
"No decurso das suas conversações, os dois ministros consideraram a situação internacional à luz dos interesses comuns e específicos dos dois países. O ministro português teve ocasião de referir alguns dos problemas externos que a Nação portuguesa confronta em África, tendo exposto as linhas gerais da política portuguesa naquele continente e salientado a sua importância para a defesa dos ideais e da segurança do mundo livre. Foi sublinhado o propósito de ambos os países continuarem a prestar a sua cooperação nos esforços gerais de desenvolvimento econômico e de expansão do comércio mundial. [...]". ${ }^{66}$

Em relação aos acordos bilaterais, Franco Nogueira expressou em seu diário exatamente o que pensava a respeito de Juracy Magalhães e dos interesses da política externa brasileira:

"Lisboa, 8 de Setembro - [...]. Ainda é o mesmo homem [Juracy Magalhães], mais temperado por uma estadia em Washington como embaixador, e sem ter sido presidente. [...]. E precauto a mais não poder: foram-lhe arrancadas a ferros as poucas frases que disse quanto ao nosso ultramar. Muito pró-americano, e ao que suspeito muito nas mãos dos americanos. Foi aliás muito nítido: depois de duas horas de uma exposição maciça que lhe fiz sobre África, disse-lhe que o Brasil nada faria quanto ao nosso ultramar, e em nosso favor, se isso prejudicasse as suas relações com os Estados Unidos. Também nada que prejudicasse os interesses brasileiros, e nisso está evidentemente certo, salvo na medida em que Juracy me parece ver os interesses brasileiros num excessivo enfeudamento a Washington, quando deveria ver que são os Estados Unidos que tremem se o Brasil, em assuntos portugueses ou latino-americanos, bate o pé a Washington, e daí a força de uma Comunidade Luso-Brasileira. Mas os acordos que assinámos a pesar de tudo [...] causaram alguma impressão, e na verdade traduzem algum apoio do Brasil à nossa política". ${ }^{67}$ (Grifos do autor).

Apesar do desapontamento demonstrado com o fracasso de suas tentativas em convencer a diplomacia brasileira a apoiar incondicionalmente a sua causa, o quadro apresentado acerca das ações do seu colega brasileiro não estava de todo equivocado. Foram demonstradas em diversas passagens acima as estreitas relações de Juracy Magalhães com os interesses estadunidenses, haja vista que ele foi um dos principais assessores de Castelo Branco na reordenação da política externa brasileira após 1964. Assumiu o posto de embaixador nos Estados Unidos com o objetivo de estreitar ainda mais os laços de dependência em relação a este país e como ministro das Relações Exteriores trabalhou no sentido de destravar qualquer possível obstáculo à livre circulação do capital estadunidense na economia brasileira. Além de imprimir uma postura de subserviência aos Estados Unidos na política externa. Foi assim na Organização dos Estados Americanos, na questão da República Dominicana, na situação de Cuba, na Guerra do Vietnam e na política racial na África do Sul, em todos estes temas, Juracy Magalhães definiu a nossa decisão a partir do alinhamento à potência hegemônica do norte.

\footnotetext{
${ }^{66}$ Diário Popular, Lisboa, 07/09/1966, p. 13.

${ }^{67}$ NOGUEIRA, Franco. Um Político Confessa-se..., p. 187-188.
} 